\title{
Lahan, Air dan Pembangunan di Kec. Marioriwawo
}

\author{
1. Nurfatimah, M.Si., Dosen Universitas Islam Negeri Alauddin Makassar; \\ nurfatimah.nurfatimah91@gmail.com \\ 2. Jumliasi, SHI., M.H, Dosen STAI DDI Kota Makassar; jumliadimh@ gmail.com \\ 3. Ardilla Abu, Dosen IAIN Palu; $\underline{\text { ardilla_abu@iainpalu.ac.id }}$ \\ 4. Fadhil Surur, S.T., M.Si., Dosen Universitas Islam Negeri Alauddin Makassar; fadhil.surur@ uin- \\ alauddin.ac.id

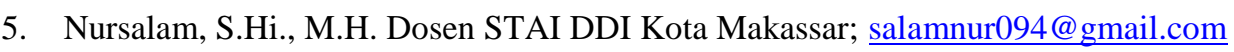

\begin{abstract}
Abstrak
Penelitian ini dilakukan untuk mengetahui kondisi daya dukung lingkungan di kec. Marioriwawo Kab. Soppeng Provinsi Sulawesi Selatan. Analisis daya dukung lahan bangunan/permukiman dan daya dukung air digunakan sebagai analisis pada penelitian ini, yang mengacu pada Permen LH No. 17 Tahun 2009. Hasil penelitian menunjukkan nilai daya dukung lingkungan sesesar 78.15 yaitu DDL > 3 maka dapat disimpulkan kondisi daya dukung lingkungan di Kec. Marioriwawo masuk dalam ketegori aman/baik berdasarkan hasil perhitungan yakni $70 \%$ daya dukung lahan bangunan dengan nilai 108,30 ha dan $40 \%$ daya dukung air dengan nilai 5.86 $\mathrm{m}^{3} /$ tahunan.
\end{abstract}

Kata Kunci: Daya Dukung, Lahan, Air, Lingkungan.

Abstrac

This research was conducted to determine the environmental carrying capacity in Marioriwawo District, Soppeng Regency, Sulawesi Selatan Province. The carrying capacities of the land for buildings and water were used for analysis in this study, referring to Environmental Ministerial Decree No. 17 of 2009. The results showed that the environmental carrying capacity was 78.15, which was more than 3 , thus categorized safe/good based on the calculation results that $70 \%$ of the carrying capacity of the building land was 108.30 hectares and $40 \%$ of the carrying capacity of water was $5.86 \mathrm{~m}^{3} /$ year.

Keywords: Carrying Capacity, Land, Water, Environment

\section{PENDAHULUAN}

Daya dukung lingkungan hidup adalah kemampuan lingkungan hidup untuk mendukung perikehidupan manusia, mahluk hidup lain, dan keseimbangan antar keduanya (Clark, 1992). Daya dukung lingkungan suatu wilayah sangat dipengaruhi oleh pertambahan jumlah penduduk dengan segala aktivitasnya yang menyebabkan kebutuhan akan lahan dan air meningkat (Afni, 2016). Peraturan Menteri Negara Lingkungan Hidup Nomor 17 Tahun 2009 tentang Pedoman Penentuan Daya Dukung Lingkungan Hidup Dalam Penataan Ruang Wilayah menyatakan bahwa penentuan daya dukung lingkungan hidup dilakukan dengan cara mengetahui kapasistas lingkungan alam dan sumber daya untuk mendukung kegiatan manusia/penduduk yang menggunakan ruang bagi kelangsungan hidup sehingga daya dukung lingkungan harus diberikan perhatian khusus agar menjaga keseimbangan antara kebutuhan dan keterbatasan dari lingkungan.

Kecamatan Marioriwawo adalah sebuah kecamatan di Kabupaten Soppeng, Sulawesi Selatan, Indonesia.. Sebagian besar wilayah dari kecamatan ini adalah daerah pegunungan, jadi tidak salah kalau daerah ini terkenal dengan suhu yang dingin dengan pemandangan alam yang sangat menyejukkan mata. Sebagian besar mata pencaharian penduduk wilayah ini adalah bertani, baik petani kebun maupun petani persawahan, hasil pertanian yang paling 
banyak dihasilkan yaitu kakao dan beras. Selain itu tidak sedikit pula penduduk dari kecamatan ini adalah pedagang dan pegawai. Wilayah ini sangat potensial di jadikan sebagai tujuan wisata, terdapat banyak tempat yang betul-betul masih alami, ditambah pemandangan persawahan yang tidak kalah dengan Ubud Bali.

Namun karena wilayah ini juga memiliki sumber daya alam yang beragam, yang mengakibatkan adanya peningkatan jumlah penduduk yang akan berdampak kepada peningkatan lagu penggunaan sumber daya alam, seperti berkurangnya ketersediaan sumber daya alam dari sektor kehutanan, maupun pertanian, termasuk pemanfaatan ruang bagi kehidupan manusia dan mahlu hidup lainnya (Sirait, 2009)

Hasil penentuan daya dukung lingkungan dapat dijadikan sebagai acuan dalam penyusunan rencana tata ruang wilayah (RTRW) yang berkelanjutan di wilayah Kec. Marioriwawo Kabupaten Soppeng. Hubungan antara daya dukung lingkungan dan RTRW yaitu dapat menentukan KLHS (Kajian Lingkungan Hidup Strategis sebagai alat yang dapat memberikan review atau evaluasi terhadap RTRW yang disusun. (Harsono, Restele, Harimuddin, \& Fitriani, 2019)

Dalam menentukan daya dukung lingkungan ini menggunakan pendekatan berbasis data spasial, yang mana informasi spasial tentang karakteristik sutau wilayah, gambaran spasial akan peruntukan dan penutupan lahan secara rinci serta pengoptimalan upaya pembangunan berbasisi lingkungan dapat diperoleh melalui Sistem Informasi Geografi (SIG).

Penelitian ini bertujuan untuk mengetahui bagaimana kondisi daya dukung lingkungan wilayah Kec. Mariorowawo Kab. Soppeng.

\section{METODE PENELITIAN}

\subsection{Lokasi Penelitian}

Penelitian ini berada di Kecamatan Mariorowawo Kabupaten Soppeng, dengan luas wilayah $59.515 \mathrm{Ha}$.

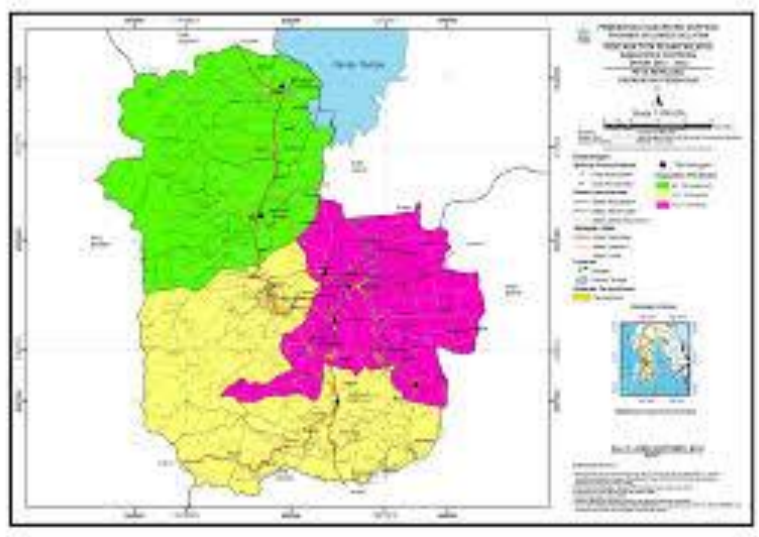

\subsection{Teknik Analisis Data}

Analisis data yang digunakan dalam penelitian ini adalah analisis daya dukung lahan bangunan/pemukiman, dan analisis daya dukung air.

\section{Analisis Daya Dukung Lahan Bangunan (Permukiman)}

Perhitungan daya dukung lahan dengan pendekatan untuk bangunan (DDLB) menggunakan persamaan yang mengacu pada Permen LH No. 17 Tahun 2009 sebagai berikut: 


$$
\begin{aligned}
& \mathrm{DDLB}=\frac{(\alpha \times \mathrm{LW})}{\mathrm{LTb}} \\
& \mathrm{LTb}=\mathrm{LB}+\mathrm{LTp}
\end{aligned}
$$

Keterangan:

DDLB = Daya dukung lahan untuk bangunan

LW = Luas Wilayah (ha)

$\mathrm{LTb} \quad=$ Luas Lahan Terbangun (ha)

LB $\quad=$ Luas Lahan Bangunan (ha)

LTp = Luas Lahan untuk Infrastruktur (seperti jalan, sungai, drainase dan lainnya (ha) jika tidak dapat diidentifikasi digunakan asumsi $20 \%$ dari luas lahan bangunan.

$\alpha=$ Koefisien luas lahan terbangun maksimal (ha) (menggunakan $70 \%$ jika pertanian $<50 \%$, menggunakan $50 \%$ jika pertanian $>50 \%$ ).

Hasil perhitungan dianalisis dengan kategori berikut:

- DDLB < 1: Daya dukung lahan pemukiman terlampaui atau buruk

- DDLB 1 - 3: Daya dukung lahan pemukiman bersyarat atau sedang

- DDLB > 3: Daya dukung lahan pemukiman aman atau baik

\section{Analisis Daya Dukung Air}

Berdasarkan Peraturan Menteri Negara Lingkungan Hidup Nomor 17 Tahun 2009, perhitungan daya dukung air dilakukan dengan membandingkan ketersediaan air (SA) dan kebutuhan air (DA) dengan formula sebagai berikut:

$$
\mathrm{DDA}=\mathrm{SA} / \mathrm{DA}
$$

Dengan,

SA : Ketersediaan air $\left(\mathrm{m}^{3} /\right.$ tahun $)$

DA: Kebutuhan Air ( $\mathrm{m}^{3} /$ tahun)

Analisis Ketersediaan Air

Persamaan untuk perhitungan ketersediaan air sebagai berikut:

$$
\begin{aligned}
& \mathrm{SA}=10 \times \mathrm{C} \times \mathrm{R} \times \mathrm{A} \\
& \mathrm{C}=\sum(\mathrm{Ci} \times \mathrm{Ai}) / \sum \mathrm{Ai} \\
& \mathrm{R}=\sum \mathrm{Ri} / \mathrm{m}
\end{aligned}
$$

Keterengan :

SA : Ketersediaan air $\left(\mathrm{m}^{3} /\right.$ tahun $)$

$\mathrm{C}$ : Koefisien limpasan tertimbang

$\mathrm{Ci}:$ Koefisien limpasan penggunaan lahan

$\mathrm{R}$ : Rata - rata aljabar curah hujan tahunan wilayah ( $\mathrm{mm} / \mathrm{tahun}$ )

Ri : Curah hujan tahunan

$\mathrm{m}$ : jumlah stasiun pengamatan curah hujan

A : Luas wilayah (ha)

Ai : Luas penggunaan lahan (ha)

Analisis Kebutuhan Air

Perhitungan kebutuhan air dihitung dengan menggunakan persamaan berikut: 


$$
\mathrm{DA}=\mathrm{N} \times \mathrm{KHL}
$$

Keterangan:

DA : Kebutuhan Air ( $\mathrm{m}^{3} /$ tahun)

$\mathrm{N} \quad$ : Jumlah penduduk (jiwa)

KHL :Kebutuhan air untu hidup layak (1600 $\mathrm{m}^{3}$ air/kapita/tahun)

Hasil perhitungan dianalisis dengan kategori berikut:

- DDA $<1$ : Daya dukung air terlampaui atau buruk

- DDA 1 - 3 : Daya dukung air bersyarat atau sedang

- DDA > 3 : Daya dukung air aman atau baik

Analisis daya Dukung Lingkungan

Status daya dukung lingkungan dengan pembobotan DDLB $70 \%$ dan DDA 40\%. Berikut perhitungan DDL :

$\mathrm{DDL}=(70 \% \mathrm{X} \mathrm{DDLB})+(40 \% \mathrm{X} \mathrm{DDA})$

- DDL $<1$ : Daya dukung lingkungan terlampaui atau buruk

- DDL 1 - 3 : Daya dukung lingkungan bersyarat atau sedang

- DDL > 3 : Daya dukung lingkungan aman atau baik.

\section{HASIL DAN PEMBAHASAN}

\subsection{Daya Dukung Lahan Bangunan}

Perhitungan daya dukung lahan bangunan (pemukiman) dilakukan dengan menghitung luas lahan bangunan pada wilayah penelitian, untuk mengetahui luas lahan bangunan di Kecamatan Marioriwawo dilakukan interpretasi citra (Tabel 1)

Tabel 1. Data Luas Guna Lahan di Kecamatan Marioriwawo

\begin{tabular}{c|lr}
\hline \multirow{2}{*}{ No. } & \multicolumn{1}{c}{ Guna Lahan } & Luas (ha) \\
\hline $\mathbf{1}$ & Hutan & 34178.43 \\
$\mathbf{2}$ & Kebun Campur & 86952.43 \\
$\mathbf{3}$ & Ladang / Tegalan & 13556.25 \\
$\mathbf{4}$ & Lahan Terbuka & 5605.25 \\
$\mathbf{5}$ & Pemukiman & 632.03 \\
$\mathbf{6}$ & Sawah & 3086.09 \\
$\mathbf{7}$ & Semak Belukar & 1830.97 \\
$\mathbf{8}$ & Tubuh Air / Sungai & 4744.86 \\
\hline Total Luas & & $\mathbf{1 5 0 5 8 6 . 3 0}$ \\
\hline Wilayah $(\mathbf{L W})$ & & \\
\hline
\end{tabular}

Berdasarkan hasil interpretasi lahan bangunan (pemukiman), luas lahan bangunan (pemukiman) di Kecamatan Mariorowawo seluas 632.03 Ha dari luas wilayah keseluruhan seluas 150586.30 Ha, Dapat di tarik kesimpulan dari sebuah perhitungan penggunaan lahan sebagai berikut: 
Jumlah penduduk $(\mathrm{JP})=45100$ jiwa

Kepadatan Penduduk $=0.299 \mathrm{jiwa} / \mathrm{ha}$

Luas Wilayah $(\mathrm{LW}) \quad=150586.30 \mathrm{ha}$

Luas Lahan Bangunan $(\mathrm{LB})=632.03$ ha

Lahan Infrastruktur (LTp) $=63.203$ ha

Koefisien luas lahan terbangun $(\alpha)=50 \%$ ha/kapita

Koefisien luas kebutuhan ruang/kapita $(\alpha)=0.0133$ ha/kapita

$\mathrm{LTb}=\mathrm{LB}+\mathrm{LTp}$

$\mathrm{LTb}=695.24 \mathrm{ha}$

DDLB $=\frac{(\alpha \times L W)}{\mathrm{LTb}}$

DDLB $=108.30$ ha

Berdasarkan perhitungan tersebut, daya dukung lahan bangunan Kecamatan Marioriwawo sebesar 108.30 ha yaitu DDLB > 3. Daya dukung lahan bangunan (permukiman) masuk dalam kategori aman/baik, sehingga kecamatan Marioriwawo masih mampu menyediakan lahan untuk bangunan/permukiman guna menampung jumlah penduduk tertentu untuk bertempat tinggal secara layak.

\subsection{Daya Dukung Air}

Daya dukung air merupakan kemampuan sumber daya air untuk memenuhi suatu kebutuhan dengan meninjau besarnya ketersediaan air. Daya dukung air dihitung berdasarkan perhitungan ketersediaan air dan kebutuhan air.

\section{Analisis Ketersediaan Air}

Perhitungan ketersediaan air dilakukan berdasarkan Permen Lhno. 17 Tahun 2009 tentang Pedoman Penentuan Daya Dukung Lingkungan Hidup dalam Penataan Ruang Wilayah. Berdasarkan hal tersebut, data yang diperlukan dalam perhitungan ketersediaan lahan, koefisien limpasan tertimbang, rata - rata aljabar curah hujan tahunan dan luas wilayah.

- Perhitungan Koefisien Limpasan Tertimbang

Perhitungan koefisien limpasan tertimbang disajikan pada tabel berikut:

Tabel 2. Data Koefisien Limpasan Tertimbang

\begin{tabular}{|c|c|c|c|c|}
\hline No. & Guna Lahan & $\begin{array}{c}\text { Luas / Ai } \\
\text { (ha) }\end{array}$ & $\begin{array}{c}\text { Koefisien } \\
\text { Limpasan } \\
\text { / Ci }\end{array}$ & $\mathbf{C i} \times \mathbf{A i}$ \\
\hline 1 & Hutan & 34178.43 & 0.18 & 6152.12 \\
\hline 2 & Kebun Campur & 86952.43 & 0.10 & 8695.24 \\
\hline 3 & Ladang / Tegalan & 13556.25 & 0.35 & 4744.69 \\
\hline 4 & Lahan Terbuka & 5605.25 & 0.35 & 1961.84 \\
\hline 5 & Permukiman & 632.03 & 0.65 & 410.82 \\
\hline 6 & Sawah & 3086.09 & 0.30 & 925.83 \\
\hline 7 & Semak Belukar & 1830.97 & 0.35 & 640.84 \\
\hline
\end{tabular}




\begin{tabular}{|l|l|r|r|r|}
\hline 8 & $\begin{array}{l}\text { Tubuh Air / } \\
\text { Sungai }\end{array}$ & 4744.86 & 0.00 & 0.00 \\
\hline TOTAL & & $\mathbf{1 5 0 5 8 6 . 3 0}$ & & $\mathbf{2 3 5 3 1 . 3 7}$ \\
\hline
\end{tabular}

Sumber : Deliniasi Peta Citra Kabupaten Soppeng
$\mathrm{C}=\frac{\sum(\mathrm{Ci} \mathrm{x} \mathrm{Ai})}{\sum \mathrm{Ai}}$
$\mathrm{C}=0.16$

- Perhitungan Rata - rata Curah Hujan tahunan diperoleh berdasarkan perbandingan curah hujan tahunan terhadap jumlah stasiun pengamatan curah hujan, seperti perhitungan berdasarkan persamaan berikut ini:

$\mathrm{R}=\frac{\sum \mathrm{Ri}}{\mathrm{m}}$

$\mathrm{R}=1756 \mathrm{~mm} / \mathrm{tahun}$

Nilai ketersediaan air di Kecamatan Marioriwawo diperoleh berdasarkan persamaan sebagai berikut:

$$
\begin{aligned}
& \mathrm{SA}=10 \times \mathrm{C} \times \mathrm{R} \times \mathrm{A} \\
& \mathrm{SA}=10 \times 0.16 \times 1756 \times 150586.30 \\
& \mathrm{SA}=423087268.48 \mathrm{~m}^{3} \text { air/tahun }
\end{aligned}
$$

\section{Analisis Kebutuhan Air}

Berdasarkan Permen LH No. 17 Tahun 2009 tentang Pedoman Penetapan Daya Dukung Lingkungan Hidup dalam Penataan Ruang Wilayah, perhitungan kebutuhan air dapat diperoleh dengan mengalikan jumlah penduduk (N) dengan Kebutuhan air untuk hidup layak (KHL) jumlah penduduk berdasarkan data Badan Pusat Statistik Kabupaten Soppeng Kecamatan Marioriwawo adalah 45100 jiwa, sedangkan kebutuhan air untuk hidup layak adalah $1600 \mathrm{~m}^{3}$ air/jiwa/tahun. Sehingga perhitungan kebutuhan air (DA) dengan menggunakan persamaan sebagai berikut:

$\mathrm{DA}=\mathrm{N} \times \mathrm{KHL}$

$\mathrm{DA}=45100 \times 1600$

$\mathrm{DA}=72160000 \mathrm{~m}^{3}$ air/tahun

Jadi, kebutuhan air pada kecamatan Marioriwawo adalah sebesar $72160000 \mathrm{~m}^{3}$ air/tahun. Sehingga hasil perhitungan dianalisis dengan persamaan berikut:

$$
\begin{aligned}
\text { DDA } & =\frac{S A}{D A} \\
\text { DDA } & =\frac{423087268.48}{72160000} \\
\text { DDA } & =5.86 \mathrm{~m}^{3} / \text { tahun }
\end{aligned}
$$

Berdasarkan hasil perhitungan antara ketersediaan air dan kebutuhan air, daya dukung air Kecamatan Marioriwawo sebesar $5.86 \mathrm{~m}^{3} /$ tahun yaitu DDA > 3. Daya dukung air masuk dalam kategori aman/baik, hal ini dikarenakan banyaknya pemenuhan kebutuhan air untuj jumlah penduduk di Kecamatan Marioriwawo. 


\subsection{Daya Dukung Lingkungan}

Kondisi daya dukung lingkungan di Kecamatan Marioriwawo dapat diketahui dengan cara menjumlahkan $70 \%$ dari daya dukung lahan bangunan dan $40 \%$ dari daya dukung air. Sehingga hasil perhitungan antara daya dukung lahan bangunan, daya dukung air dan daya dukung lingkungan sebesar 78.15 yaitu DDLP > 3. Daya dukung lingkungan masuk dalam kategori aman/baik, hal ini dikarenakan ada beberapa indikator yang mendukung daya dukung lingkungan yakni daya dukung lahan bangunan yang aman/baik sehingga masih mampu menyediakan lahan bangunan untuk menampung jumlah penduduk agar dapat bertempat tinggal secara layak dan daya dukung air di kecamatan Marioriwawo juga masih memiliki ketersediaan air yang lebih besar dibandingkan dengan kebutuhan air penduduknya.

\section{KESIMPULAN}

Berdasarkan tujuan dan hasil penelitian, maka dapat disimpulkan bahwa daya dukung lahan bangunan/permukiman Kecamatan Marioriwawo adalah sebesar 108.30 ha yaitu DDLB > 3. Daya dukung lahan bangunan (permukiman) masuk dalam kategori aman/baik, sehingga kecamatan Marioriwawo masih mampu menyediakan lahan untuk bangunan/permukiman guna menampung jumlah penduduk tertentu untuk bertempat tinggal secara layak. Sedangkan daya dukung air Kecamatan Marioriwawo sebesar $5.86 \mathrm{~m}^{3} /$ tahun yaitu DDA > 3. Daya dukung air masuk dalam kategori aman/baik, hal ini dikarenakan banyaknya pemenuhan kebutuhan air untuj jumlah penduduk di Kecamatan Marioriwawo.

Maka dar itu, berdasarkan hasil perhitungan daya dukung lingkungan diperoleh sebesar 78.15 yaitu DDLP > 3. Maka dapat disimpulkan bahwa kondisi daya dukung lingkungan di Kecamatan Marioriwawo Kabupaten Soppeng masuk dalam kategori amana/baik.

\section{DAFTAR PUSTAKA}

Afni, N. (2016). Daya Dukung Lingkungan Kecamatan Pattalassang Kabupaten Takalar. Jurnal Perencanaan Wilayah dan Kota, 74-85.

Badan Pusat Statistik. (2019). Kecamatan Marioriwawo dalam Angka 2019. Soppeng: BPS Soppeng

Clark, J. R. (1992). Intragated Management Of Coastal Zones. United Nation/FAO, Rome: FAO Fisheries Technical Paper No. 327.

Harsono, A. R., Restele, L. O., Harimuddin, J., \& Fitriani, F. (2019). Analisis Daya Dukung Lingkungan Kawasan Perkotaan Andolo Kabupaten Konawe Selatan. JAGAT (Jurnal Geografi Aplikasi dan Teknologi , 29-40.

Peraturan Menteri Negara Lingkungan Hidup Nomor 17 Tahun 2009. Pedoman Penentuan Daya Dukung Lingkungan Hidup Dalam Penataan Ruang WIlayah. 22 Mei 2009. Lembaran Negara Republik Indonesia Tahun 2007 Nomor 68, Tambahan Lembaran Negara Republik Indonesia Nomor 3699. Jakarta

Sirait, J. (2009). Konsep Pengembangan Kawasan Kota. Wahana Hijau. Jurnal Perencanaan dan pengembangan Wilayah Vol.4 No.3 , 142-152. 
